(1)

CrossMark

\title{
Fatty airways: a source of good and bad fats?
}

\author{
Christopher E. Brightling ${ }^{1}$, Andrew B. Tobin² and Graeme Milligan²
}

Affiliations: ${ }^{1}$ Institute for Lung Health, Leicester NIHR Biomedical Research Centre, University of Leicester, Leicester, UK. ${ }^{2}$ Centre for Translational Pharmacology, Institute of Molecular, Cell and Systems Biology, College of Medical, Veterinary and Life Sciences, University of Glasgow, Glasgow, UK.

Correspondence: Christopher E. Brightling, University of Leicester, Glenfield General Hospital, Leicester, LE3 9QP, UK. E-mail: ceb17ale.ac.uk

@ERSpublications

Adipose tissue is increased around the airway in asthma and is associated with BMI, airway inflammation and disease severity. Fat in the airway might contribute both positively and negatively to the immunobiology of asthma. http://bit.ly/2CgOGsY

Cite this article as: Brightling CE, Tobin AB, Milligan G. Fatty airways: a source of good and bad fats? Eur Respir J 2019; 54: 1902060 [https://doi.org/10.1183/13993003.02060-2019].

There is a constant and consistent message in the medical and lay press that obesity is a modern epidemic affecting the developed world. It causes and exacerbates multiple diseases including cardio-metabolic, musculoskeletal, cancer and respiratory diseases [1]. There is no doubt that improving diet and lifestyle to eliminate obesity has positive health benefits [1]. Although this truism is well-known and accepted, the impact of obesity on the immunobiology of disease [1-4] is only beginning to be unravelled and this might reveal more subtle, albeit profound, effects of obesity on chronic inflammatory diseases.

Obesity is a major risk factor for the development of asthma [5]. Prospective epidemiological studies demonstrate consistently that obesity can antedate a diagnosis of asthma [6]. As body mass index (BMI) and fat mass increases, the relative risk of developing asthma increases, asthma-related health status and symptoms worsen and exacerbations become more frequent [7]. Obesity-associated asthma may represent a distinct clinical phenotype, characterised by later onset, female preponderance and greater symptomatology than classic atopic asthma with a relatively low degree of eosinophilic inflammation measured by sputum cytology $[8,9]$. Obesity is more common in severe asthma with, strikingly, the majority of severe asthmatics in many developed countries now living with obesity as a major comorbidity [9].

Obesity will cause extrathoracic restriction and is reported to promote airway hyperresponsiveness, most likely via increased airway closure [10]. This is related to obesity but not waist circumference [11], suggesting the effects might not simply be due to poor inspiratory effort due to diaphragmatic splinting but could be due to additional factors. Several studies have demonstrated that weight reduction by diet and exercise or bariatric surgery improve asthma outcomes, including symptoms, airway hyperresponsiveness and exacerbation frequency [12-15]. Even though these benefits are considered to be predominantly via reduction of extrathoracic restriction some, but not others, suggest an impact on airway inflammation [12-14], highlighting the possibility that the impact upon asthma outcomes might be partly via the effect of obesity upon the immunobiology of the disease [2-4].

As noted above obese asthmatics typically have low eosinophil numbers in their airway measured by sputum analysis. However, obesity itself is associated with a small increase in blood eosinophils [16]. Interestingly, bronchial tissue eosinophils are increased in obesity in spite of a lack of sputum eosinophils [17]. An explanation for this apparent paradox has begun to be revealed by human in vivo tracking of eosinophils [18]. 
Using radiolabelled eosinophils coupled with SPECT/CT to quantify eosinophilic inflammation in patients with asthma revealed important differences in eosinophil kinetics between obese and non-obese asthmatic subjects. Eosinophil retention in the airway is prolonged in obese asthmatics, suggesting that there is altered behaviour of eosinophils in asthma subjects with obesity. In this issue of the European Respiratory Journal, ELLiot et al. [19] report that adipose tissue lies in the outer airway wall and is increased in fatal asthma and those that died with asthma of other causes compared to non-asthmatics. The granulocytic inflammation, both neutrophilic and eosinophilic, was related to the amount of adipose tissue in the airway. The adiposity in the airway was associated with BMI. This adipose tissue in the airway could be an epiphenomenon but perhaps represents an important source of local cytokines and adipokines, such as leptin, that impact on inflammatory cell trafficking and survival and consequently enhance airway inflammation and possibly remodelling.

Many metabolic products, including fatty acids of varying chain length, modulate homeostatic control by activating members of the G protein-coupled receptor (GPCR) superfamily. A pair of receptors, FFA1 and FFA4 (also designated GPR40 and GPR120, respectively) is activated by many distinct long chain fatty acids (>12 carbon atoms) [20] that are stored within adipose tissue as triglycerides and, given the expression of these receptors in many metabolically active tissues and in a wide range of immune cells, there has been considerable interest in targeting either FFA1 and/or FFA4 to treat conditions such as type II diabetes [21]. However, although high level expression of FFA4 in the lung, and potentially by club cells, was identified more than 10 years ago [22] few studies have explored its potential to regulate airway contraction. FFA1 and FFA4 are expressed in human and guinea pig airway smooth muscle, and FFA1 agonists potentiated acetylcholine-induced contraction of guinea pig tracheal rings [23]. Although FFA4 is sometimes described erroneously as a receptor for polyunsaturated omega-3 fatty acids [24], efforts to directly link the effects of such fatty acids to the biology of FFA4 is hampered by their conversion to resolvins which play key roles in resolving lung inflammation [25]. There is clearly a need to better understand the contribution of adipose tissue, fatty acids, and both FFA1 and FFA4 in both normal and diseased lung.

Beyond the local effects within the airway, obesity is associated with increased low-grade systemic inflammation characterised by increases in systemic levels of inflammatory cytokines, such as interleukin (IL)-6, IL-1 and tumour necrosis factor, and adipokines, such as leptin [26]. These mediators originate in adipocytes and activated macrophages in adipose tissue, and together with hyperinsulinaemia and insulin resistance [27] contribute to mechanisms of metabolic dysfunction and metabolic syndrome in asthmatics with obesity. Obese patients with high IL-6 levels have more severe asthma than obese patients with low IL-6 levels [28]. This asthma metabolic syndrome might be amenable to treatments targeting insulin resistance and inflammation, such as anti-IL-6 biological therapies.

Whilst weight reduction via diet and lifestyle must remain the mainstay of management for asthmatics with obesity, it is important to consider the varied role of adiposity in the immunobiology of asthma. Systemic anti-inflammatory strategies to target metabolic syndrome might be valuable especially in those with elevated blood IL-6. Eosinophil and T2-directed therapies might be beneficial even in the absence of sputum eosinophilia due to altered eosinophil cell trafficking and retention in the airway. Consideration of lipids in particular triglycerides as immunomodulatory bioactive lipid mediators that impact on airway inflammation and remodelling might make us reconsider the role of "fat" in the airway, with some fats possibly having a beneficial role as "good fats", whereas other "bad fats" are deleterious for asthma.

Acknowledgements: This paper contains independent research funded by the National Institute for Health Research (NIHR) Leicester Respiratory Biomedical Centre. The views expressed are those of the authors and not necessarily those of the NHS, the NIHR or the Department of Health.

Conflict of interest: C.E. Brightling reports grants and personal fees for consultancy from AZ, GSK, Novartis, Chiesi, Gossamer, 4DPharma, BI and Mologic, grants from Merck and Genentech/Roche, and personal fees for consultancy from TEVA and Sanofi, outside the submitted work. A.B. Tobin has nothing to disclose. G. Milligan is director of Calden Therapeutics.

\section{References}

1 Heymsfield SB, Wadden TA. Mechanisms, pathophysiology, and management of obesity. N Engl J Med 2017; 376: 254-266.

2 Kim HY, Lee HJ, Chang YJ, et al. Interleukin-17-producing innate lymphoid cells and the NLRP3 inflammasome facilitate obesity-associated airway hyperreactivity. Nat Med 2014; 20: 54-61.

Umetsu DT. Mechanisms by which obesity impacts upon asthma. Thorax 2017; 72: 174-177.

4 Scott HA, Gibson PG, Garg ML, et al. Airway inflammation is augmented by obesity and fatty acids in asthma. Eur Respir J 2011; 38: 594-602.

5 Peters U, Dixon AE, Forno E. Obesity and asthma. J Allergy Clin Immunol 2018; 141: 1169-1179.

6 Beuther DA, Sutherland ER. Overweight, obesity, and incident asthma: a meta-analysis of prospective epidemiologic studies. Am J Respir Crit Care Med 2007; 175: 661-666. 
7 Hjellvik V, Tverdal A, Furu K. Body mass index as predictor for asthma: a cohort of 118,723 males and females. Eur Respir J 2010; 35: 1235-1242.

8 Haldar P, Pavord ID, Shaw DE, et al. Cluster analysis and clinical asthma phenotypes. Am J Respir Crit Care Med 2008; 178: 218-224.

9 Gibeon D, Batuwita K, Osmond $\mathrm{M}$, et al. Obesity-associated severe asthma represents a distinct clinical phenotype: analysis of the British Thoracic Society Difficult Asthma Registry Patient cohort according to BMI. Chest 2013; 143: 406-414.

10 Burgess JA, Matheson MC, Diao F, et al. Bronchial hyperresponsiveness and obesity in middle age: insights from an Australian cohort. Eur Respir J 2017; 50: 1602181.

11 Peters U, Subramanian M, Chapman DG, et al. BMI but not central obesity predisposes to airway closure during bronchoconstriction. Respirology 2019; 24: 543-550.

12 Dixon AE, Pratley RE, Forgione PM, et al. Effects of obesity and bariatric surgery on airway hyperresponsiveness, asthma control, and inflammation. J Allergy Clin Immunol 2011; 128: 508-515.

13 van Huisstede A, Rudolphus A, Castro Cabezas M, et al. Effect of bariatric surgery on asthma control, lung function and bronchial and systemic inflammation in morbidly obese subjects with asthma. Thorax 2015; 70: 659-667.

14 Dias-Júnior SA, Reis M, de Carvalho-Pinto RM, et al. Effects of weight loss on asthma control in obese patients with severe asthma. Eur Respir J 2014; 43: 1368-1377.

15 Hasegawa K, Tsugawa Y, Chang Y, et al. Risk of an asthma exacerbation after bariatric surgery in adults. J Allergy Clin Immunol 2015; 136: 288-294.

16 Vuong J, Qiu Y, La M, et al. Reference intervals of complete blood count constituents are highly correlated to waist circumference: should obese patients have their own "normal values?". Am J Hematol 2014; 89: 671-677.

17 Desai D, Newby C, Symon FA, et al. Elevated sputum interleukin-5 and submucosal eosinophilia in obese individuals with severe asthma. Am J Respir Crit Care Med 2013; 188: 657-663.

18 Farahi N, Loutsios C, Tregay N, et al. In vivo imaging reveals increased eosinophil uptake in the lungs of obese asthmatic patients. J Allergy Clin Immunol 2018; 142: 1659-1662.

19 Elliot JG, Donovan GM, Wang KCW, et al. Fatty airways: implications for obstructive disease. Eur Respir J 2019; 54: 1900857.

20 Christiansen E, Watterson KR, Stocker CJ, et al. Activity of dietary fatty acids on FFA1 and FFA4 and characterisation of pinolenic acid as a dual FFA1/FFA4 agonist with potential effect against metabolic diseases. Br J Nutr 2015; 113: 1677-1688

21 Milligan G, Alvarez-Curto E, Hudson BD, et al. FFA4/GPR120: pharmacology and therapeutic opportunities. Trends Pharmacol Sci 2017; 38: 809-882.

22 Miyauchi S, Hirasawa A, Iga T, et al. Distribution and regulation of protein expression of the free fatty acid receptor GPR120. Naunyn Schmiedebergs Arch Pharmacol 2009; 379: 427-434.

23 Mizuta K, Zhang Y, Mizuta F, et al. Novel identification of the free fatty acid receptor FFAR1 that promotes contraction in airway smooth muscle. Am J Physiol Lung Cell Mol Physiol 2015; 309: L970-L982.

24 Oh DY, Talukdar S, Bae EJ, et al. GPR120 is an omega-3 fatty acid receptor mediating potent anti-inflammatory and insulin-sensitizing effects. Cell 2010; 142: 687-698.

25 Duvall MG, Bruggemann TR, Levy BD. Bronchoprotective mechanisms for specialized pro-resolving mediators in the resolution of lung inflammation. Mol Aspects Med 2017; 58: 44-56.

26 Peters MC, Fahy JV. Metabolic consequences of obesity as an "outside in" mechanism of disease severity in asthma. Eur Respir J 2016; 48: 291-293.

27 Peters MC, McGrath KW, Hawkins GA, et al. Plasma interleukin-6 concentrations, metabolic dysfunction, and asthma severity: a cross-sectional analysis of two cohorts. Lancet Respir Med 2016; 4: 574-584.

28 Cardet JC, Ash S, Kusa T, et al. Insulin resistance modifies the association between obesity and current asthma in adults. Eur Respir J 2016; 48: 403-410. 